\title{
Consumer Skepticism towards Advertising on Television Media
}

\section{Amit Kumar*}

Haryana School of Business, Guru Jambheshwar University of Science and Technology, Hisar, India

\begin{abstract}
Purpose: Aim of this study is to examine the level of consumer skepticism towards the brand claims advertising and how it is affected by consumer's demographic profile.

Design/methodology/approach: The scale developed by Obermiller and Spangerberg is used in this study for measuring consumer skepticism towards advertising. And for the purpose of analysis of data chi-square, correlation and uni-variate analysis tools were used.

Findings: The results show that consumer's gender and age have influence on consumer skepticism towards the brand advertising on television.

Practical implications: By understanding consumer skepticism towards advertising, marketers could overcome problems related to failure of brand advertising.
\end{abstract}

Keywords: Consumer; Skepticism; Advertising; Television

\section{Introduction}

For advertising TV media is widely used for marketing the wide range of products, from food category products to launching of new cars into the market. Television remains the most effective medium for reaching today's customers and it also is most efficient for introducing people to brands. Advertising through television allows marketers to show and tell a wide audience your business, product, or service. Television appeals to the literate as well as the illiterate and this is one feature of TV that makes it unique and different from other mediums. Television is treated as "The King" of the advertising media; Because $\mathrm{TV}$ is the most entertaining media, almost every person like to spend more time in watching TV per day than spending time with any other medium. It is most interesting and entertaining medium for advertising because it has the capabilities to make an object interesting and attractive by the use of sight, color, sound and motion. TV has proved its persuasive power in influencing human behavior from time to time. It is popular than other media because of its creativity and impact, coverage and cost effectiveness, captivity and attention, selectivity and flexibility. The interaction of sight and sound offers wonderful creative flexibility and makes dramatic life like representation of products possible. TV commercials can be used to express a mood or image for a brand as well as to develop emotional or entertaining appeals that help to make dull products appear interesting.

Advertising is one of the important tools of promotion mix for informing and communicating the consumers about the brands available in the market and variety of products useful to them, advertising is an influential communication for persuading and convincing the consumers to buy company's product services or ideas. Advertising is a non-personal communication of information usually paid for and usually persuasive in nature about products, services or ideas by identified sponsors through the various media [1]. For promotional strategy advertising is considered as a major component of creating awareness and conditional factor in the mind of the consumer to make purchase decision. Though advertising can reach to wide range of targeted audience, advertising is not always well welcomed as approximately $70 \%$ of consumers perceive advertising to be unfaithful [2].

Every year a huge amount is invested by lot of companies to advertise their products so that they can inform and persuade wide no of consumers, but this investment is not always welcomed by consumers so the investment on advertising and its purpose become meaningless. This advertising investment becomes ineffective because by having trust on TV advertising consumer also have some level of distrust on advertising. This distrust or doubt towards advertising is called consumer skepticism towards advertising. In simple understanding the word skepticism can be defined as doubt towards some specific object. In this way we can define consumer skepticism towards television advertising as consumers doubt or suspect towards the claims made relating to advertised products in the advertisements on television. Figure 1 depicted how skepticism comes into existence.

The process of consumer skepticism towards advertising is explained by the above construct in Figure 1. Marketers/advertisers for communicating and advertising of their products choose the media and on that particular media, make statements of advertising claims to the targeted audience related to their products. After watching the advertisements consumers in response to the advertising claims may show positive or negative response. If there is a negative response which means consumer has doubt on advertising claims, this doubt is known as consumer skepticism towards advertising which in turn affect the marketers in terms reducing purchases of consumers, creating a negative image about company and its products and most importantly it can the advertising investment meaningless. In this study we are going to find how the Indian television advertising is affected by consumer skepticism towards advertising.

\section{Literature Review and Hypotheses}

\section{Consumer skepticism toward advertising}

There is significant evidence of considerable consumer skepticism

*Corresponding author: Amit Kumar, Research Scholar, Haryana School of Business, Guru Jambheshwar University of Science and Technology, Hisar, India Tel: +91-9582830827; E-mail: amitgautam996@gmail.com

Received March 31, 2018; Accepted April 17, 2018; Published April 24, 2018

Citation: Kumar A (2018) Consumer Skepticism towards Advertising on Television Media. J Account Mark 7: 267. doi: 10.4172/2168-9601.1000267

Copyright: (C) 2018 Kumar A. This is an open-access article distributed under the terms of the Creative Commons Attribution License, which permits unrestricted use, distribution, and reproduction in any medium, provided the original author and source are credited. 


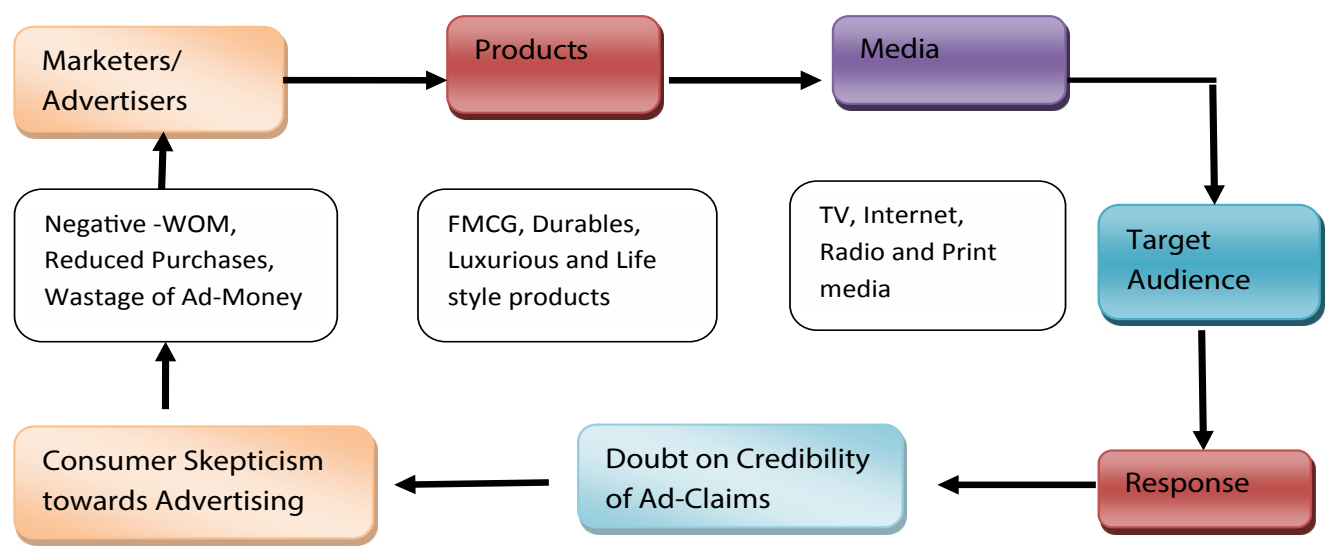

Figure 1: Construct of consumer skepticism towards advertising.

toward advertising (CSA). According to Calfee and Ringold [2], approximately $70 \%$ of US in general consumers are skeptical of advertising, although they believe it provides valuable information. The study also found that most of the consumers in their study have believed that advertising has the only goal to make them buy the things they do not want and it should be more strictly regulated.

Researchers have examined the origin of skepticism toward advertising through consumer socialization view, developmental process thinking and learning by which young people acquire the knowledge, attitudes and in the marketplace [3]. Skepticism results through interaction with socialization agents such as parents, peers, and the mass media [4].

Consequently, it should be positively associated with marketplace knowledge that stems from socialization agents. For instance, family communication as an important socializing factor may increase consumers' knowledge and skills in the marketplace [5], which in turn may speed up the development of skeptical attitudes toward advertising.

Obermiller and Spangenberg [6] gave the definition of consumer skepticism towards advertising as the general tendency of doubts towards the advertising claims. In this study it was stated that consumer skepticism is influenced by situational factors. Forehand and Grier [7] agreed with Obermiller and further expand the concept of consumer skepticism and discussed about two types of skepticism: predispositional and situational skepticism. Pre-dispositional skepticism is defined as the continuing inclination to have doubt on the marketer's motives. Situational skepticism differs from this concept; this type of skepticism may positively or negatively be influenced by marketers. The study also state that message formulation and situational variables can influence consumer skepticism.

As one of the most common attitudes of consumers toward advertising, skepticism is a critical approach to respond effectively to advertising messages [4]. It is an important skill for consumers to acquire due to the powerful consequences it may cause. For example, a skeptical consumer is likely to doubt the credibility of advertising, which in turn may weaken the acceptance of the advertising claim [8]. Similar effects have also been found in other studies in terms of the relation of skepticism and specific advertising variables, such as attention to ads, efforts to avoid advertising, reliance on ads, brand beliefs, and responses to informational and emotional appeals. For instance, Obermiller et al. [9] discovered that consumers who have developed a highly skeptical tendency toward advertising are less likely to like advertising and, therefore, are less likely to attend to or rely on it.

As another significant socialization agent, the mass media also can influence the consumer skepticism. When consumers confronts with different type of media, consumers have different level of skepticism towards advertising [10].

\section{Consumer skepticism toward TV advertising}

Mangelburg and Bristol [4] found that American adolescents who watch more television are more likely to recognize differences among ads in truthfulness and therefore become more skeptical toward advertising.

Boush et al. [11] examined adolescents' skepticism towards advertising on TV, found that adolescent were highly skeptical of TV advertising and as they grow their level of skepticism due to increased understanding of advertisers tactics. On the opposite of this, Tian and Pasadeos [12] concluded that, consumer are less skeptical of advertising on TV in comparison of print media.

\section{Hypotheses}

1. There is a difference of skepticism within gender.

H0: male and female have same level of skepticism.

H1: male and female differ in level of skepticism.

2. Education influence skepticism.

H0: education has no influence on skepticism.

H1: education influence skepticism.

3. Age and skepticism are correlated.

H0: Age has no influence on skepticism.

H1: age influence skepticism.

4. Timing of viewing advertising also effect skepticism.

H0: timing of viewing advertising does not influence skepticism.

$\mathrm{H} 1$ : timing of viewing advertising influence skepticism.

\section{Research Methodology}

Obermiller and Spangenberg's [6] 9 items Likert Skep-scale was used to measure skepticism in the study. Data were collected from 
city Delhi, India, from 86 respondents. Questionnaire were collected from both males and females, all the respondents were adults, having age more than 17 years starting from age 18 years. All the respondents were literate. Data was collected from rational consumer (adult and educated). For analyzing the data Chi-Square $\left(\mathrm{x}^{2}\right)$ test, univariate analysis and correlation were conducted.

Sample Profile: Total of 86 subjects completed the questionnaire. Among them, 53 were female, about $72 \%$ of them having age group of 18-25 year old. And 33 were male respondents $45 \%$ of them were of age group 18-25 year old. Table 1 depicts the profile of respondents.

\section{Analysis and Results}

Hypothesis 1: There is a difference of skepticism within gender.

In chi-square test $\mathrm{p}$ value found $<0.5$ so we reject the $\mathrm{H} 0$ : male and female have same level of skepticism. And accept the H1: male and female differ in level of skepticism. As shown in Table 2.

Hypothesis 2: Education influence skepticism.

As shown by Tables 2 and 3 we found in our study that there is difference between consumers skepticism towards advertising within gender. Male were found to be overall more skeptic than females.

Tables 4 and 5 above depicts that there is a positive relation between consumers' education status and consumer skepticism towards

\begin{tabular}{|l|l|c|c|c|c|}
\hline \multirow{2}{*}{$\begin{array}{l}\text { Age } \\
\text { (in years) }\end{array}$} & Gender & \multicolumn{4}{|c|}{ Education } \\
\cline { 3 - 6 } & & UG & Graduated & PG & Other \\
\hline $18-25$ & Male & 12 & 3 & 0 & 0 \\
\hline \multirow{2}{*}{$26-35$} & Female & 31 & 5 & 2 & 0 \\
\hline \multirow{3}{*}{$36-45$} & Male & 2 & 5 & 3 & 0 \\
\cline { 2 - 6 } & Female & 2 & 6 & 1 & 0 \\
\hline \multirow{3}{*}{$46-65$} & Male & 2 & 3 & 2 & 0 \\
\hline & Female & 1 & 3 & 1 & 1 \\
\hline & Male & 0 & 1 & 0 & 0 \\
\cline { 2 - 6 } & Female & 0 & 0 & 0 & 0 \\
\hline
\end{tabular}

Table 1: Respondents profile.

\begin{tabular}{|l|c|c|c|}
\hline & Value & Df & Asymp. Sig. (2-sided) \\
\hline Pearson Chi-Square & $36.569^{\mathrm{a}}$ & 18 & 0.006 \\
\hline Likelihood Ratio & 46.959 & 18 & 0.000 \\
\hline N of Valid Cases & 86 & & \\
\hline
\end{tabular}

Df: Degree of freedom; ${ }^{a} p<0.5$

Table 2: Chi-Square Test.

\begin{tabular}{|l|c|c|c|}
\hline \multicolumn{4}{|c|}{ Dependent variable: Skepticism } \\
\hline Gender (independent variable) & Mean & Std. Deviation & N \\
\hline Male & 3.3603 & 0.46732 & 33 \\
\hline Female & 3.2034 & 0.64889 & 53 \\
\hline Total & 3.2636 & 0.58796 & 86 \\
\hline
\end{tabular}

Table 3: Descriptive statistics: Gender and skepticism.

\begin{tabular}{|l|l|c|c|c|}
\hline \multirow{5}{*}{ Skepticism } & Searson's correlation & 1 & 0.108 & \multirow{2}{*}{ Skepticism } \\
\cline { 2 - 4 } & Sig. (2-tailed) & & 0.322 & \\
\cline { 2 - 4 } & $\mathrm{N}$ & 86 & 86 & \\
\hline \multirow{2}{*}{ Education } & Pearson's correlation & 0.108 & 1 & \multirow{2}{*}{ Education } \\
\cline { 2 - 4 } & Sig. (2-tailed) & 0.322 & & \\
\cline { 2 - 4 } & $\mathrm{N}$ & 86 & 86 & \\
\hline
\end{tabular}

Table 4: Correlation between education and skepticism. advertising, since $\mathrm{p}$ value is $>0.05$ so we don't reject the null hypothesis (H0), i.e., education has no influence on skepticism.

Hypothesis 3: Age and skepticism are correlated.

Tables 6 and 7 prove that consumer skepticism towards advertising is strongly and positively influenced by Age. Since p value is $<0.05$ we are going to accept $\mathrm{H} 1$ : age influence skepticism.

Hypothesis 4: Timing of viewing advertising also effect skepticism.

Table 8 depict that there is a positive relationship between consumer skepticism towards advertising and timing of viewing advertising on televisions but there is no significant relationship. Since the value is greater than 0.05 so we are going to accept the H0: timing of viewing advertising does not influence skepticism.

\section{Findings and General Discussion}

The present study illustrates the influence of consumer's demographic profile on consumer's skepticism towards advertising on television. In the first finding, the results show that amount of

\begin{tabular}{|l|l|c|c|c|}
\hline \multicolumn{5}{|c|}{ Dependent variable: Skepticism } \\
\hline Gender & Education (independent variable) & Mean & Std. Deviation & N \\
\hline \multirow{5}{*}{ Male } & GG & 3.1736 & 0.50832 & 16 \\
\cline { 2 - 5 } & Graduated & 3.5648 & 0.26573 & 12 \\
\cline { 2 - 5 } & PG & 3.4667 & 0.55221 & 5 \\
\cline { 2 - 5 } & Total & 3.3603 & 0.46732 & 33 \\
\hline & UG & 3.1830 & 0.67163 & 34 \\
\cline { 2 - 5 } & Graduated & 3.2937 & 0.67461 & 14 \\
\cline { 2 - 5 } & PG & 3.1389 & 0.53190 & 4 \\
\cline { 2 - 5 } & Other & 2.8889 & & 1 \\
\cline { 2 - 5 } & Total & 3.2034 & 0.64889 & 53 \\
\hline & Total & 3.2636 & 0.58796 & 86 \\
\hline
\end{tabular}

Table 5: Descriptive statistics: education and skepticism.

\begin{tabular}{|l|l|c|c|}
\hline & & Age & Skepticism \\
\hline Age & Pearson Correlation & 1 & $0.279^{* *}$ \\
\hline & Sig. (2-tailed) & & 0.009 \\
\hline \multirow{2}{*}{ Skepticism } & N & 86 & 86 \\
\hline & Pearson Correlation & $0.279^{* *}$ & 1 \\
\hline & Sig. (2-tailed) & 0.009 & \\
\hline & N & 86 & 86 \\
\hline
\end{tabular}

Table 6: Correlation between age and skepticism.

\begin{tabular}{|c|c|c|c|c|}
\hline \multirow{2}{*}{ Age (years) } & \multicolumn{2}{|c|}{ Gender } & \multicolumn{2}{c|}{ Skepticism (mean) } \\
\cline { 2 - 5 } & Male & Female & Male & Female \\
\hline $18-25$ & 15 & 38 & 3.1852 & 3.1520 \\
\hline $26-35$ & 10 & 9 & 3.4444 & 3.1235 \\
\hline $36-45$ & 7 & 6 & 3.5238 & 3.6481 \\
\hline $46-65$ & 1 & 0 & 4.0000 & 0 \\
\hline Total & 33 & 53 & 3.3603 & 3.2034 \\
\hline
\end{tabular}

Table 7: Descriptive statistics: age, gender and skepticism.

\begin{tabular}{|l|l|c|c|}
\hline \multirow{3}{*}{ Time } & & Time & Skepticism \\
\cline { 2 - 3 } & Pearson's correlation & 1 & 0.084 \\
\cline { 2 - 3 } & Sig. (2-tailed) & & 0.444 \\
\cline { 2 - 4 } Skepticism & N & 86 & 86 \\
\cline { 2 - 4 } & Pearson's correlation & 0.084 & 1 \\
\cline { 2 - 4 } & Sig. (2-tailed) & 0.444 & 86 \\
\hline & N & 86 & \\
\hline
\end{tabular}

Table 8: Correlations between time and skepticism. 
skepticism could be different between male and female consumers. Results showed that male consumers tend to be more skeptical than women. Table 3 shows that skepticism of male consumer was 3.3603 and of females was 3.2034 .

The next finding shows that education of consumer is positively correlated with consumer's skepticism towards advertising on TV. But it was not significantly correlated. As shown in Table 5 , consumers who graduated male and female were both shown highest level of skepticism than other education categories.

In next finding study showed that age has a positive and significant correlation with skepticism towards advertising on TV. As shown in Table 7, as the consumer's age increases consumer's skepticism towards advertising on TV tends to increase too. This tendency was found in both male and females. It shows that as consumer grows old have more experiences and achieve more knowledge he tend to become more skeptic of advertising.

In our last finding, the timings of viewing advertising on television have positive but not a significant influence on consumer's skepticism towards advertising on TV. This study has included three timings of viewing television ads-At any particular time, between favorite programs or whenever they are telecasted. Table 9 represents consumer's skepticism its relation with skepticism. It shows that female's skepticism for advertising is higher when they view advertising between their favorite programs. This tells that females don't want to see advertising while watching their favorite TV serials or program. So marketers need to understand this tendency to improve their advertising effectiveness. And on the opposite of this male consumers found to be more skeptical at a specific time period.

\begin{tabular}{|l|l|c|c|c|}
\hline Gender & Time & Mean & Std. Deviation & N \\
\hline \multirow{3}{*}{ Male } & Between favorite program & 3.0370 & 0.77194 & 6 \\
\cline { 2 - 5 } & Whenever they telecast & 3.4222 & 0.32584 & 15 \\
\cline { 2 - 5 } & At a particular time & 3.4444 & 0.39921 & 12 \\
\cline { 2 - 5 } & Total & 3.3603 & 0.46732 & 33 \\
\hline \multirow{3}{*}{ Female } & Between favorite program & 3.2407 & 0.69547 & 30 \\
\cline { 2 - 5 } & Whenever they telecast & 3.1204 & 0.44307 & 12 \\
\cline { 2 - 5 } & At a particular time & 3.1919 & 0.74716 & 11 \\
\cline { 2 - 5 } & Total & 3.2034 & 0.64889 & 53 \\
\hline
\end{tabular}

Table 9: Descriptive statistics: Time and skepticism.

\section{Conclusion}

Future research should focus on further elucidating the process (es) through which advertising messages influence consumer judgment. In addition, some attention should be devoted to a greater sample size and consumer's occupation and its influence on skepticism towards advertising. This study didn't include the type of advertising, so future research should include the types of advertising and its impact on consumer skepticism towards advertising. For example, informational advertising, motivational advertising, sexual content advertising and funny advertisings and their influence on consumer skepticism towards advertising on television.

\section{References}

1. Bovee CL, Arens WF (1992) Contemporary advertising. Homewood.

2. Calfee JE, Ringold DJ (1994) The $70 \%$ majority: Enduring consumer beliefs about advertising. J Public Policy Mark 13: 228-238.

3. Lowery SA, De Fleur ML (1988) Milestones in mass communication effects. Longman, New York, NY.

4. Mangelburg T, Bristol T (1998) Socialization and adolescents' skepticism toward advertising. J Advert 27: 11-21.

5. Moschis GP, Churchil GA (1978) Consumer socialization: A theoretical and empirical analysis. J Mark Res 15: 599-609.

6. Obermiller C, Spangenberg ER (1998) Development of a scale to measure consumer skepticism toward advertising. J Consumer Psychol 7: 159-186.

7. Foreh MR, Grier S (2003) When is honesty the best policy? The effect of stated company intent on consumer skepticism. J Consumer Psychol 13: 349-356.

8. Holbrook MB (1978) Beyond attitude structure: Toward the informational determinants of attitude. J Mark Res, pp: 545-556.

9. Obermiller C, Spangenberg E, MacLachlan DL (2005) Ad skepticism: The consequences of disbelief. J Advert 34: 7-17.

10. Alwitt LF, Prabhaker PR (1992) Functional and belief dimensions of attitudes to television advertising: Implications for copytesting. J Advert Res.

11. Boush DM, Friestad M, Rose GM (1994) Adolescent skepticism toward TV advertising and knowledge of advertiser tactics. J Consumer Res 21: 165-175.

12. Tian S, Pasadeos $Y$ (2012) Chinese consumers' skepticism toward advertising China Media Research 8: 64-76. 